\title{
"All'idea di quel metallo": Ideas económicas en algunas óperas de comienzos del XIX
}

\author{
Miguel-Ángel Galindo Martín ${ }^{\text {a }}$, MARÍA-Teresa MÉNdez PiCAZo ${ }^{\text {b }}$ \\ ${ }^{a}$ Universidad de Castilla-La Mancha, Facultad de CC.EE, Plaza de la Universidad, 1, 02071 \\ Albacete, España.E-mail:mgalindomar@orange.es \\ ${ }^{b}$ Universidad Complutense de Madrid, Facultad de CC.EE., Campus de Somosaguas, 28223 Pozuelo \\ de Alarcón (Madrid), España. E-mail: mmendezpi@ccee.ucm.es
}

\section{RESUMEN}

A partir del siglo XVIII y especialmente durante el XIX, la economía va confirmándose como una ciencia social, separándose de otras formas del conocimiento humano. Las publicaciones en este campo ofrecen principios y leyes de comportamiento a una sociedad que estaba experimentando cambios importantes de índole social. El objetivo de este artículo es explicar cómo algunas óperas han introducido ideas económicas en sus argumentos, centrándonos en el caso de las óperas del inicio del siglo XIX y de autores italianos, exponiendo sus aportaciones respecto al emprendedor, los precios y la gobernanza

Palabras Clave: Precios, gobernanza, emprendedor, Rossini, armonía.

\section{"All'Idea di quel Metallo": Economic Ideas in Some Operas at the Beginning of the 19th Century}

\begin{abstract}
From the century 18th and especially 19th century, the economy is considered as a social science, separating from other forms of human knowledge. Publications in this field supply principles and laws of behavior, to a society that was experiencing major social changes. The aim of this article is to explain how some operas have introduced economic ideas in their arguments, focusing in the case of the operas of beginning of the 19th century and Italian authors, exposing their contributions with regard to the entrepreneur, prices and governance.
\end{abstract}

Keywords: Prices, Governance, Entrepreneur, Rossini, Harmony.

Clasificación JEL: Z11

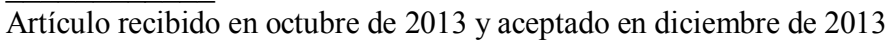

Artículo disponible en versión electrónica en la página www.revista-eea.net, ref. ə-32113 


\section{INTRODUCCIÓN}

A partir del siglo XVIII y especialmente durante el XIX, la economía va confirmándose como una ciencia social, separándose de otras formas del conocimiento humano. Las publicaciones en este campo ofrecen principios y leyes de comportamiento a una sociedad que estaba experimentando cambios importantes de índole social. En este sentido, Bigelow (2003, p. 2) señala que con el crecimiento de una sociedad industrial y de mercado a lo largo del siglo XIX se produjo una división entre el ámbito económico y el cultural.

Esta "nueva" disciplina, a la que Carlyle llegó a denominar "ciencia lúgubre", llamó la atención también de escritores y compositores, y no siempre desde un punto de vista positivo. Los efectos económicos que se estaban produciendo en la sociedad se recogían en sus escritos y obras y afectaban a la vida y situación de sus personajes, suponiendo en algunos casos el leit-motiv de la obra.

No es de extrañar, por tanto, que no sólo los economistas se preocupasen de transmitir las ideas de esta disciplina, sino que también otros intelectuales, escritores, pintores, músicos, etc., se ocupasen de esta materia y plasmaran sus ideas en su obras.

En este sentido, se ha prestado una gran atención al ámbito de la literatura y existe una amplia bibliografía en la que se analizan las ideas económicas expuestas en novelas, obras de teatro, etc. La ópera, sin embargo, ha sido analizada en menor medida, a pesar de que en ella, como es sabido, se pone música a un texto, generalmente procedente de una obra que ha tenido una cierta repercusión o ha despertado el interés de un empresario o compositor, y recogiendo en ocasiones en los libretos algunas de las ideas económicas.

El objetivo de este artículo es analizar los planteamientos económicos que se recogen en algunas óperas. Es una tarea muy complicada y difícil dentro de las limitaciones lógicas de un artículo. Por ello hemos restringido el estudio considerando sólo el ámbito temporal y territorial y centrándonos en los comienzos del siglo XIX.

Para llevar a cabo nuestro objetivo, hemos dividido el artículo en cuatro partes. Tras una primera parte introductoria, la segunda hace referencia al papel del emprendedor, la tercera a la determinación de los precios, la cuarta a la gobernanza y la quinta expone algunas conclusiones.

\section{2. "ALL'IDEA DI QUEL METALLO": EL EMPRENDEDOR ROSSINIANO}

Una de las óperas en las que la actividad económica desempeña un papel relevante es sin duda El Barbero de Sevilla (Il barbiere di Siviglia o Almaviva, ossia L'inutile precauzione) de Gioachino Rossini. Estrenada en 1816, se basa 
en la obra del mismo título escrita por Pierre-Agustin de Beaumarchais, que como es sabido, fue un dramaturgo francés conocido tanto por la obra citada, como por su continuación Las Bodas de Fígaro, a la que Mozart puso música en una ópera con el mismo título.

A diferencia de lo que ocurre con otras obras, en este caso existe la gran ventaja de poder comparar el libreto de Cesare Sterbini con la obra original y con la de otros libretistas que también la utilizaron, siendo durante mucho tiempo El barbero de Sevilla, o la precaución inútil (Il barbiere di Siviglia, ovvero La precauzione inutile), compuesta por Giovanni Paisiello en 1782, la más representativa y significativa hasta el estreno de la obra de Rossini. La comparación entre estas obras nos permite comprobar que los elementos económicos son de mayor relevancia en la obra de Rossini que en las anteriores, supuestamente ante el mayor protagonismo que estaba cobrando la actividad económica en el momento de su estreno.

En efecto, Beaumarchais nos presenta en su obra a un Fígaro alegre y bebedor, muy diferente de la presentación de Rossini en su famoso "Largo al Factotum", como se recoge a continuación:

\begin{tabular}{|c|c|c|}
\hline Beaumarchais & Paisiello & Rossini \\
\hline $\begin{array}{l}\text { "Eliminemos la pena, } \\
\text { que nos consume } \\
\text { sin el fuego del buen vino } \\
\text { que nos enciende, } \\
\text { obligado a languidecer, } \\
\text { el hombre sin placer, } \\
\text { como un tonto viviría } \\
\text { y en morir no tardaría (...) } \\
\text { El vino y la pereza } \\
\text { mi corazón se reparten, } \\
\text { si una es mi dueña } \\
\text { el otro es mi servidor (...)" } \\
\text { (Beaumarchais, } 1775, \text { pp. 291-292) }\end{array}$ & $\begin{array}{l}\text { "Eliminemos la pena } \\
\text { Que nos causa daño } \\
\text { que con el vino } \\
\text { nos hace agradables } \\
\text { y cálidos. } \\
\text { Un hombre sin vino pobrecito, } \\
\text { pronto morirá como un necio" }\end{array}$ & $\begin{array}{l}\text { “¿Dejen paso al factótum de la } \\
\text { ciudad (...)! } \\
\text { ¡Rápido a la tienda } \\
\text { que ya es de día! (...) } \\
\text { Dispuesto a hacer de todo, } \\
\text { de noche y de día (...) } \\
\text { Todos me llaman } \\
\text { todos me solicitan (...)” } \\
\text { (Rossini, 1983, p. } 59)\end{array}$ \\
\hline
\end{tabular}

Como se puede observar, hay grandes diferencias. A pesar de que Paisiello lima algunos aspectos no muy aceptables de Fígaro que aparecen en Beaumarchais, en ninguna de las dos obras parece una persona confiable. Además le han despedido del empleo que le había conseguido el conde, y eso tampoco da buena impresión de él. Parece más bien un tunante que se aprovecha de las circunstancias.

En cambio, Sterbini y Rossini nos presentan a un Fígaro muy distinto. En su caso se trata de un emprendedor que busca las distintas oportunidades que le ofrece su negocio para subsistir y obtener un beneficio. No piensa en el vino, sino en las actividades que puede realizar para satisfacer de la mejor manera posible las demandas que se le hacen: Está "dispuesto a hacer de todo: llevar pelucas, hacer la barba, llevar cartas...", etc., es decir, no sólo las actividades típicas de un barbero, sino también las de mensajero o de celestino, si se pre- 
senta el caso. Este comportamiento de emprendedor schumpeteriano parece tener éxito, y gracias a su innovación-genio, destruye la competencia ("creación destructiva"), como parece indicar en el recitativo que sigue a su cavatina "Largo al factótum", cuando dice que en Sevilla sin su intervención no se casa ninguna jovencita y que incluso la viuda recurre a él para encontrar marido. Además le gusta su trabajo, ya que "disfruta mucho y se cansa poco". Asimismo cuida su reputación, ya que es lo que le permite tener siempre dinero en el bolsillo.

Se ha escrito mucho sobre el temor que tenían Sterbini y Rossini a hacer enfadar a los seguidores de Paisiello, que veneraban su ópera y consideraban una audacia imperdonable que alguien pudiera tratar de superarla. Pero ya fuera a causa de dicho temor, o porque los tiempos iban cambiando y surgían nuevas actividades comerciales, Sterbini y Rossini presentan una trama que introduce ciertos cambios respecto a la de Beaumarchais-Paisiello, sobre todo en el carácter de los personajes.

Si Mozart en Don Giovanni refleja el ocaso de una clase social, representada por su protagonista, que ya no consigue tan fácilmente sus objetivos y que acaba desapareciendo (el protagonista es arrastrado a los infiernos), Rossini nos muestra la evolución de los miembros de la sociedad, tanto los que representan el nuevo orden y la nueva sociedad (Fígaro, Rosina y el Conde de Almaviva), como los que representan el viejo orden (el médico Don Bartolo y Don Basilio, el tutor de Rosina).

Ambos mundos luchan de forma distinta: en el nuevo se imponen las transacciones monetarias, el ingenio y la innovación, frente al viejo, donde priman la "calumnia" y el respeto al estatus establecido (reflejado en el aria "A un doctor de mi clase"), y que intenta imponerse no mediante la razón, sino a través del castigo (Rosina debe quedarse encerrada en su cuarto hasta que su tutor decida permitirle salir).

La forma de alcanzar el objetivo de casarse con Rosina es diferente en los casos de Bartolo y del conde. El conde, a través de Fígaro, utiliza la imaginación y el dinero, tal y como expresan ambos en su dúo "All' idea di quel meta1lo" (A la idea de ese metal). En él, Fígaro va contando las formas que se le ocurren de entrar en casa de Bartolo, inspirándose en el oro (a modo de financiación-recompensa) que le va dando el conde. No podía ser de otra forma, ya que estamos en un mundo comercial donde no se trabaja gratis, por lo que el conde debe pagar por la tarea realizada, en este caso, por las innovaciones. El conde pasa a ser el financiador de Fígaro, quién se ve estimulado por el oro, y no por la servidumbre, ni por la amistad, etc., que son los valores del viejo orden. Si no hay dinero la iniciativa no sigue adelante.

Al inicio de la ópera, ya se muestra esta misma situación cuando los músicos exigen al conde el pago de la serenata nocturna que ofrece a Rosina, y es recri- 
minado por su tacañería al no mostrarse demasiado generoso.

Hay que resaltar también el carácter diferente del conde y de Fígaro. El primero representa al amante enamorado que, en el dúo al que nos referimos, mientras ofrece oro a Fígaro, piensa en lo dichoso que será cuando consiga casarse con Rosina:

"Con ardor insólito

mi alma se enciende...

iAh que de amor

la llama siento..."

Fígaro, en cambio, es un hombre práctico y negociador que quiere ver recompensados sus servicios mediante el pago y que indica al conde que su bolsa debe estar llena de dinero. Si el conde canta al amor, Fígaro piensa en el oro:

¡Ya oigo el sonido de las monedas!

(....)

Ya llega la hora, ya está,

ya oigo el sonido de las moneas,

ya llega el oro, llega la plata..." (Rossini, 1983, pp. 75-76)

El segundo aspecto también recogido en dicho dúo es la tienda, símbolo de distinción de Fígaro. Cuando el conde le pregunta dónde está situada, por si necesitara sus servicios, Fígaro se la describe, detallando el escaparate, fachada etc., Bartolo y Basilio actúan de forma muy diferente. Como se ha dicho antes, siguen utilizando medios antiguos, como el honor, la reputación, etc. Un ejemplo de ello es el aria de Basilio "La calumnia", donde recomienda utilizarla para disuadir al conde de su propósito, pues "el infeliz calumniado, bajo el látigo público, podrá sentirse feliz si muere". Pero como es sabido, no tendrán éxito: en la sociedad comercial el honor tiene mucha menos importancia que antes, hacen falta recursos, ingenio, innovaciones y sobre todo dinero para tener éxito. Y Fígaro y el conde disponen de todo ello.

\section{3. "UNO SCUDO REGALAR": EL PRECIO}

El estudio de la formación de los precios ha sido estudiado por parte de los economistas, mostrando las distintas circunstancias que afectan a su formación, distinguiendo entre mercados competitivos y no competitivos (monopolísticos). En términos generales, desde la perspectiva clásica, el precio se determina a través de la oferta y la demanda, sin que aparentemente funcione otro principio especifico (Sowell, 2006, p. 68). Más tarde, Leon Walras expondría su idea del subastador para obtener el precio de equilibrio en un mercado competitivo, basándose en las subastas que hacían los campesinos franceses a lo largo del siglo XVIII.

Algunas de estas ideas se recogen en las dos óperas que comentamos a con- 
tinuación. La primera de ellas es La Cambiale di Matrimonio de Rossini, estrenada en 1810, con libreto de Gaetano Rossi basado en obra de Camillo Federici (1791) y en un libreto previo de Giuseppe Checcherini para la ópera de Carlo Coccia, Il matrimonio per lettera de cambio (1807). En esta obra de un solo acto se narra el contrato de matrimonio que hace un hombre de negocios canadiense, Mr. Slook, mediante una letra de cambio para que su corresponsal Tobia Mill le busque esposa. Este considera que su hija (Fanny) es la mejor opción, pero ésta está enamorada de Milfort y tras varias peripecias ambos consiguen que al final Slook gire la letra en favor de Milfort.

Slook considera el matrimonio como una actividad empresarial y a su mujer un artículo que tiene que reunir una serie de características, tal y como lo expone en la carta que le envía a su corresponsal:

"Señor...

He decidido formar

una empresa matrimonial (...).

No sirve cualquier dote.

Tiene que ser de clase honesta.

No tenga más de treinta años,

un carácter dulce

y sin mancha en su reputación.

Con temperamento sano y robusto

para resistir el viaje por mar y el clima, (...)"

En definitiva, como Norton (el contable de Tobia) le dice a Milfort cuando le explica la petición de Slook:

"Como si estuviese en un mercado...

Como si la señorita

fuese una bella mercancía."

Pero Slook no contaba con el comportamiento de Fanny, que le recrimina "Yo no soy una mercancía". Sin embargo, a lo largo de la obra se sigue tratando a Fanny como tal: en el enfrentamiento con Milford, Slook le dice que Fanny "es una mercancía de mi propiedad"; cuando Norton quiere explicarle a Slook que puede tener problemas para conseguir casarse con Fanny y éste le pregunta por qué, Norton le indica que Fanny "está hipotecada" (dando a entender que está enamorada de otro); cuando Slook pide explicaciones a Fanny sobre la situación, le pregunta por el comprador de la hipoteca y ella señala a Milford. les:

Al final de la ópera, Slook resume todo el problema en términos comercia-

"Vuestra hija es un capital

la habéis hipotecado

contra su voluntad..." 
Y la solución que propone es la de ceder (vender) la letra a un tercero, en este caso Milford, que se haga cargo de la mercancía. No pone precio a la cesión, ya que en realidad "la mercancía" es muy costosa para él. Como sigue considerando el tema como un negocio, añade que las ganancias del mismo consistirán en dar "un nieto dentro de un año".

Tobia queda satisfecho y considera que "Con buen juicio el negocio (el matrimonio) marchará".

La segunda obra a considerar es L'Elisir d'Amore, de Gaetano Donizetti y libreto italiano de Felice Romani, basado en el libreto francés Le philtre (1831) de Eugène Scribe escrito para la ópera de Daniel-François Auber, según la obra de Silvio Malaperta Il filtro. En ella se ofrece otro tipo de mercancía, cuyo precio va variando a lo largo de la obra según la necesidad que se tiene de ella. Estrenada en 1832, nos cuenta en concreto las andanzas de un campesino, Nemorino, que está enamorado de Adina, una rica hacendada, que en principio no le presta atención. Al comienzo, Adina lee a sus trabajadores la historia de cómo Tristán consiguió el amor de Isolda gracias a un elixir. A partir de entonces, Nemorino trata de conseguir ese brebaje que le permitirá, según cree, conquistar el corazón de Adina.

Entre tanto, llega al pueblo un curandero engañabobos, que se hace llamar Doctor Dulcamara, que vende una mercancía que, según él, alivia toda dolencia. En su aria presenta, como buen vendedor, un producto cuya competitividad se basa en una gran cantidad de "poderes" (el listado que hace de sus ventajas es enorme). Pero también se comporta como un subastador walrasiano, ya que baja el precio hasta donde considera que puede vaciar el mercado:

"Me preguntaréis, ¿cuánto cuesta,

cuánto vale la botella?

¿Cien escudos...

treinta ...veinte?

(La gente da muestras de no querer cómprala a ese precio)

No..., que nadie se asuste.

Para probaros $m i$

agradecimiento (...)

quiero, buena gente, un escudo regalar" (Donizetti, 1983, p. 51)

Nemorino le pregunta si tiene el elixir que utilizó Tristán, y Dulcamara, sorprendido al principio, pero viendo el negocio, le dice que sí, y le vende vino, siendo su precio todo el dinero que lleva el campesino. En el dúo se muestra como el oferente, Dulcamara, se da cuenta de la necesidad del demandante, Nemorino, y saca todo el partido que puede: le proporciona una mercancía que, a pesar de que no va a tener los efectos que espera el demandante, convence a éste de sus propiedades gracias a la información que le da y a que Nemorino no 
analiza las características del productor; y así, creyendo en el "marketing" de Dulcamara, le da todo el dinero que tiene.

La cosa se complica, ya que Dulcamara, para que no se dé cuenta del engaño, asegura que el efecto del brebaje no se produce hasta el día siguiente, que es cuando espera dejar el pueblo. Pero Adina ha decidido casarse ese mismo día con un sargento. Por tanto, Nemorino necesita un elixir más poderoso cuyos efectos sean más inmediatos. De nuevo Dulcamara le ofrece la solución, un nuevo elixir pagando el precio que le pide.

Hasta este momento, la obra nos ha transmitido cómo se fija se precio en el mercado desde una posición monopolística, tanto por parte de la oferta como de la demanda, teniendo Dulcamara una posición de ventaja al estudiar mejor la situación del mercado y darse cuenta de la imperiosa necesidad que tiene $\mathrm{Ne}$ morino de ese producto.

A partir de aquí, la lección que se extrae de la obra desde el punto de vista económico se refiere al valor del producto. Si Nemorino le daba un elevadísimo valor, ya que pensaba que era el único remedio para conseguir el amor de Adina, se comprueba que las mujeres no le dan ninguno y que depende de su situación. El valor recae en dos ámbitos principalmente. En primer lugar, las muchachas del pueblo que empiezan a fijarse en Nemorino y a considerarle como opción matrimonial porque ha heredado de un pariente y se convierte en millonario:

“Así, pues, Nemorino

es millonario, es el rico

Epulón del vecindario,

hombre de valía

un buen partido...

¡Feliz la que se case con él!’. (Donizetti, 1983, p. 79)

Dulcamara cambia de idea respecto al valor del elixir al comprobar que las muchachas persiguen a Nemorino con la idea de casarse, y piensa "comercializar" el producto, vendérselo a cualquiera que tenga "mal de amores" y obtener el correspondiente beneficio.

En segundo lugar, el comportamiento de Adina, que a pesar de ser una potencial compradora del brebaje, se muestra furiosa ante el despecho de Nemorino, que se marcha rodeado de muchachas que quieren casarse con él. Dulcamara le dice que ello se debe al elixir que él elabora y que puede fabricárselo, a lo que ella responde que sólo quiere conquistar a un hombre, que no le "preocupan las riquezas" y que no quiere el elixir porque que "hay otro de mayor efecto", que hará que Nemorino abandone a las otras por ella: "una tierna miradita, una sonrisa, una caricia..." En definitiva, Adina le dice a Dulcamara:

"El remedio es mi mirada 
en estos ojos está el elixir" (Donizetti, 1983, p. 87)

Pero Dulcamara sigue viendo las posibilidades de negocio y de beneficios y no abandona la idea de vender un brebaje que:

"puede en un instante,

no sólo remediar

el mal de amor

sino también enriquecer

a los pobres." (Donizetti, 1983, p. 93)

$\mathrm{Y}$ en efecto, como había calculado, hay muchos incautos que le compran el elixir que ha preparado, y le despiden considerándole como el "fénix de los doctores" y deseando que vuelva pronto a la aldea.

\section{4. "GLI AFFETI ORMAI TACCIANO": PASIONES Y GOBERNANZA}

A lo largo de la historia se ha desarrollado una importante literatura que muestra la necesidad de que exista armonía en las sociedades para que éstas puedan progresar de una forma adecuada sin generar problemas que puedan dañar severamente su evolución (Galindo y Méndez, 2011).

Desde el punto de vista económico, este planteamiento ha sido considerado bajo la perspectiva de lo que se ha denominado como "armonía de los intereses". Dicho concepto se asocia especialmente con Frédéric Bastiat, quien consideraba que en una sociedad se alcanzará una armonía cada vez mayor si todos los hombres tratan de conseguir su propio desarrollo sin restricciones en el uso de sus facultades y disponiendo libremente de los frutos del trabajo que llevan a cabo. Además, ello se permitirá que se genere un progreso cada vez mayor (Bastiat, 1850).

En concreto, Bastiat consideraba que cuando las personas buscan su propio interés no hay conflicto de intereses, ya que la ganancia de uno no supone pérdida para otro, por lo que se produce dicha armonía. Además, los individuos pueden aprovecharse de los efectos beneficiosos derivados de la división del trabajo y del libre cambio, de tal manera que tanto el productor como el consumidor se ven beneficiados por el proceso (Roche, 1993). Sólo la actuación de los políticos y del gobierno puede evitar que se produzca dicha armonía. La intervención estatal ejerce una influencia negativa, ya que tendrá que aumentar los impuestos para sufragar el gasto que genera, que además, o bien no proporciona nada que sea útil para sociedad, o bien los individuos pueden realizar por ellos mismos lo que realiza el estado. El único efecto beneficioso derivado de la intervención estatal sería la protección de la propiedad privada y la penalización de aquéllos que traten de coartar a la sociedad.

Hay que tener en cuenta también que esta "armonía de los intereses" no es 
equivalente a la idea de equilibrio. Como señala Thornton (2007, p. xiii), "Los teóricos del equilibrio consideraron que la idea de la armonía de Bastiat competía con su propio concepto de equilibrio (...), porque mientras el equilibrio es como mucho una ficción, armonía es una idea precisa de lo que realmente sucede en un mundo de libre mercado. Por lo tanto, el equilibrio puede en algunos casos ser una copia o igualar a la armonía, pero también puede aplicarse a fines equivocados y ser inaplicable en otros".

En este ámbito es importante el papel que desempeña el gobernante, ya que como indica Bastiat, su mala actuación puede perjudicar la consecución de dicha armonía. Debido a ello, Erasmo, por ejemplo, señalaba la necesidad de evitar que el rey se convirtiera en tirano, ya que entre otras cuestiones: "El tirano pretende ser temido; el rey se desvela por ser amado. El tirano ninguna cosa tiene por tan sospechosa como la concordia de los buenos ciudadanos y de las ciudades entre sí..." (Erasmo, 1516, p. 292). Por ello es imprescindible contar con buenos asesores para evitar caer en un mal gobierno.

Esta perspectiva también se puede encontrar en algunas de las óperas del entorno que estamos considerando. Así, Rossini en su ópera Armida, estrenada en 1817, con libreto en italiano de Giovanni Schmidt, basado la obra de Torquato Tasso Jerusalén liberada, nos cuenta cómo durante la primera cruzada, la reina de Damasco y hechicera Armida enamora al caballero cruzado Rinaldo, haciéndole abandonar su ejército para vivir en la que ella bautiza como "Isla de la Fortuna”, en la que sólo hay armonía, paz y amor, gracias a la varita mágica que ella posee:

"Esta es la isla

que llaman de la fortuna,

sólo por mí conocida.

Aqui olvidaremos todo rencor

pues todo respira paz y amor."

Rinaldo queda hechizado ante las maravillas que observa y todos viven como canta el coro del final de acto II:

"Todo exhala el aroma de Armida:

paz, amor, felicidad y amistad.

Todo está sometido al reino de Armida,

todo cede donde impera la belleza".

Pero el gobierno que ejerce Armida es engañoso, ya que bajo su mandato también vive y actúa un ejército de diablos dispuesto a subyugar a aquéllos que la bruja considere enemigos. Así pues, ese mundo feliz que nos describe dicho acto es engañoso, hay una falsa armonía, ya que puede desaparecer en cualquier momento, cuando el ejército de diablos de Armida ataque a los que ella considere sus enemigos. Pero Rinaldo siente tal pasión por Armida que no le deja ver 
la realidad. Afortunadamente cuando sus amigos van a rescatarle la razón se impone, y dándose cuenta del peligro que corren, abandona a Armida.

Otra situación es la que nos expone en su ópera Ermione, estrenada en 1819, con libreto en italiano de Andrea Leone Tottola, basado en la obra Andrómaca de Racine. En ella narra la vuelta de Pirro, hijo de Aquiles, a su país, tras haber participado en la guerra de Troya, trayéndose como prisioneros a Andrómaca, viuda de Héctor y a su hijo Astianate. Pirro desea casarse con la viuda de Héctor, pero esta le rechaza y tras amenazar con matar a Astianate si no accede, Andrómaca da falsamente su consentimiento, lo que enfurece a Ermione, hija de Menelao y Helena, que está enamorada de Pirro. Ésta, en venganza, convence a Orestes, hijo de Agamenón y Clitemnestra, para que mate a Pirro, lo que al final sucede. Cuando Orestes le muestra a Ermione el puñal ensangrentado, ella se horroriza y pide a las Furias que se la lleven; Orestes aturdido, es salvado y sacado del país por sus compañeros.

El comportamiento del trio protagonista de la ópera es un ejemplo de cómo el conflicto de intereses y la pasión que se desencadena entre los individuos no sólo impiden la armonía que señalaba Bastiat, sino que ponen en peligro a los países implicados. Ni siquiera son escuchados los asesores a los que tanta importancia da Erasmo como se ha indicado antes. Así por ejemplo, cuando Orestes se encamina a cumplir su misión, su amigo y consejero Pílades le aconseja:

"Hijo de Agamenón,

guíate a partir de ahora de la razón,

no hagas caso de tus pasiones

¡Escucha sólo la voz de tu deber!”

Y añade que ante sus deseos y tentaciones, debe buscar "refugio en la amistad".

Por su parte, Pirro, en su afán de conseguir casarse con Andrómaca, utiliza todo tipo de tretas, amenazas, cariño..., tal y como muestra en la gran escena del acto I. Pero dicha intención pone en peligro la paz con los griegos y su pueblo se siente descontento y atemorizado por la situación. Cree que va a poder satisfacer su pasión casándose con Andrómaca y no le importa amenazar a los pueblos helenos e incluso llegar a la guerra con ellos.

Ermione es el tercer personaje en discordia y el que pone en marcha el proceso, lo que supone una importante desviación respecto al texto de Racine, cuyo personaje principal es Andrómaca, que da nombre a la obra. Como no podía ser de otra forma, Ermione está furiosa por el desprecio que le ha hecho Pirro al no querer casarse con ella, y al darse cuenta de la pasión de Orestes, le convence para que mate a Pirro.

Cuando Orestes finalmente cumple lo que le ha pedido Ermione y se lo cuenta, ésta enloquece y le increpa duramente: le llama loco y le acusa de ser 
"peor que cualquier animal salvaje". Le llama "asesino y traidor", recriminándole no haberla interpretado bien y no haber sabido "leer en sus labios". Al fin y al cabo, era una mujer despechada que amaba un hombre y en la furia del momento había dicho y pedido cosas que no deseaba.

En definitiva, la falta de control de las pasiones provoca que los tres personajes salgan mal parados: Pirro es asesinado, Orestes huye del país sin cumplir sus objetivos: hacerse con el hijo de Héctor y casarse con Ermione; y ésta acaba loca por seguir su pasión, a diferencia de lo que le sucede en la obra de Racine, donde muere.

Se pueden encontrar más ejemplos de cómo los intentos de conseguir el propio interés no benefician necesariamente a la sociedad en una de las óperas más conocidas de Giuseppe Verdi, Rigoletto. Estrenada en 1851, con libreto italiano de Francesco Maria Piave basado en la obra teatral Le Roi s'amuse, de Víctor Hugo, se cuenta cómo el Duque de Mantua, siguiendo sus instintos e intereses, destruye las vidas de su bufón Rigoletto y de Gilda, la hija de éste. El duque, "joven, alegre, poderoso, guapo", como le describe el bufón, tiene un alma negra y pérfida y un comportamiento egoísta, y no le importa perjudicar a los que le rodean. Puede tener momentos de ternura y de contrición, como indica en el aria "Me parece estar viendo las lágrimas" del acto II, pero todo es fugaz. Así, cuando sus cortesanos le brindan la oportunidad de satisfacer su pasión por Gilda (a la que tienen secuestrada), olvida todo y vuelve a las andadas (lo que queda reflejado en la cabaletta "Poderoso amor me llama"). Rigoletto, por el contrario, es deforme, pero tiene una ternura de la que carece el Duque, aunque centrada sólo en su hija. Todo se vuelve contra él, desencadenándose lo que él llama la "Maledizione", ya que debido a un engaño, el asesino que ha contratado para matar al duque mata a su hija. En su conflicto de interés con la sociedad que le rodea sale perdiendo. De todos, el "bello" y rico Duque sale ganando, y a diferencia de lo que ocurría en Ermione, parece que el poder y la riqueza se confabulan para evitar el castigo. De todas formas, cabe cuestionarse si puede progresar una sociedad como la del Duque, que sólo persigue el lujo y los placeres y cuyos cortesanos tienen como único objetivo, como les increpa Rigoletto, conseguir oro.

Pero no siempre es así. En su tercera ópera Nabucco, estrenada en 1842, con libreto en italiano de Temistocle Solera basado en el Antiguo Testamento y en la obra Nabuchodonosor, de Francis Cornue y Anicète Bourgeois, Verdi muestra como la pasión que gobierna al rey Nabucco y que le conduce a perder su posición, su trono e incluso a ser detenido y encarcelado, le hace más humano y justo (en este caso, siguiendo el camino marcado por los principios justos de Jehová) llegando a restablecer su posición y consiguiendo que su pueblo prospere, ya que como se dice al final de la obra "iSirviendo a Jehová tú serás rey de reyes!”. 


\section{5. "TUTTO CANGIA, IL CIEL SI ABBELLA": CONCLUSIONES}

Mozart presenta en La Flauta Mágica, estrenada en 1791, con libreto en alemán de Emanuel Schikaneder, la posibilidad de que los hombres puedan vivir en un mundo feliz, ya sea siguiendo sus pasiones, aunque no de forma desenfrenada, o mediante la razón. Los primeros están representados por Papageno, el pajarero, que no busca las "delicias celestiales" que le ofrece el Orador, sino "un buen vaso de vino", que le parece muy superior a esa otra delicia. Mientras sus necesidades más básicas puedan ser satisfechas, no habrá problemas, porque gracias a ello podrá casarse con Papagena y tener más Papagenos como él que le harán feliz, siempre y cuando las teorías maltusianas de la población no se cumplan.

Junto a ellos están los que buscan utilizar la razón, siendo la sabiduría su premio, como es el caso de Pamina, Tamino y Sarastro. Ahora bien, este grupo tampoco está exento de pasiones, que si no se controlan pueden perjudicarles como le ocurre a la Reina de la Noche. Pero Mozart parece indicar que cualquiera puede acceder a ese nivel de sabiduría y todos los hombres pueden vivir felices. Su temprana muerte no nos permite saber si Mozart hubiera desarrollado más esta idea en obras posteriores.

Rossini, en su última ópera, Guillermo Tell, estrenada en 1823, con libreto francés de Étienne de Jouy e Hippolyte Bis basado en la obra Wilhelm Tell de Friedrich Schiller, también nos ofrece su visión de la sociedad. Tras las luchas, tiranías y pasiones desenfrenadas, también recogidas en sus obras anteriores, como se ha indicado, el compositor italiano se despide de la producción operística diciendo "Tutto cangia, il ciel si abbella", esto es,

"Todo cambia, el cielo se despeja,

el aire se purifica.

$$
\text { (...) }
$$

La naturaleza también está satisfecha.

$$
\text { (...) }
$$

Donde quiera que se mire

toda la dulzura aparece de nuevo".

Rossini ofrece un canto a la naturaleza, hacia la que debemos volver nuestros ojos e intereses, preservándola porque nos proporciona lo que necesitamos y olvidándonos de las pasiones e intereses, que sólo aportan daños y problemas.

Son dos visiones que podrían considerarse complementarias, que nos indican las posibilidades que tiene el ser humano para seguir progresando y ser feliz.

Obviamente, el análisis realizado es susceptible de ser ampliado considerando obras de otros ámbitos geográficos, como las óperas alemanas y francesas, así como otros periodos temporales y temas, como el del comportamiento de los empresarios teatrales. 


\section{REFERENCIAS BIBLIOGRÁFICAS}

BASTIAT, F. (1850): “The Law”, en The Bastiat Collection, vol. 1, Alabama: Ludwig Von Mises Institute [2007].

BEAUMARCHAIS, P. A. DE (1775): Le Barbier de Séville, Bibliothèque de la Pliade, París: Gallimard [1998]

BIGELOW, G. (2003): Fiction, Famine, and the Rise of Economics in Victorian Britain and Ireland, Cambridge: Cambridge University Press.

DONIZETTI, G. (1983): “L’Elisir d'Amore”, Madrid: Daimon, traducción de Xosé Aviñoa.

ERASMO DE ROTTERDAM (1516): Educación de príncipe cristiano, Madrid: Ed. Aguilar [1964]

GALINDO, M.A. y MÉNDEZ, M.T. (2011): “Utopías y economía: la importancia del progreso armónico", Revista de Responsabilidad Social de la Empresa, Volume 3, number 3, pp. 255-290.

ROSSINI, G. (1983): /l Barbiere di Siviglia, Madrid: Daimón, traducción de Roger Alier.

ROCHE, G. (1993): Free Markets, Free Men: Frederic Bastiat 1801-1850, Hillsdale: Hillsdale College Press.

SOWELL, T. (2006): On Classical Economics, New Haven: Yale University Press.

THORNTON, M. (2007). "Introduction", en The Bastiat Collection, vol.1, Alabama: Ludwig Von Mises Institute, pp. IX-XV. 